\title{
Mustard surgery three months after a covid-19 infection: a case report
}

\begin{abstract}
Introduction: This past year, on a global scale, since 2019, public health warnings have gone off because of the recent epidemiological crisis set of the Covid-19 pandemic. This pandemic holds responsibility for millions of infections, manifesting broadly in its clinical presentation, which ranges from asymptomatic carriers to respiratory failure, myocardial pathology and death; increasing the rates of hospitalization. Pediatric patients are at high risk of contracting the disease including those with congenital cardiomyopathy that are in need of surgical intervention in order to survive.

Objective: Show that there exists an opportunity for elective surgical treatment and short term and medium term recovery in these patients in spite of respiratory and cardiovascular sequelae. Case presentation of an eleven-month infant diagnosed with Transposition of the Great Vessels, who after three months of idleness for having tested positive for Covid-19, received definitive surgical care for the initial diagnosis.

Results: The perioperative strategy was based in the probable sequelae due to the infection. There are not respiratory complications like consequence for the previous lung injury. The auriculoventricular dysfunctional immediate post-operative was related with the surgical technique. Conclusion: A period no less than three months could be offer security for surgery using extracorporeal circulation in pediatric patients who suffered covid-19. Patient with favorable post-op prognosis resulting from the work of a multi-disciplinary team that met all challenges of the complications inherent in the post-operative period following a complex cardiovascular surgery along with those of a potentially fatal virus.
\end{abstract}

Keywords: congenital cardiomyopathy, transposition of the great vessels, mustard, covid19 disease, surgery post covid-19
Volume 7 Issue I - 2022

\author{
Ilen Corrales Arredondo,' C Alfredo Mario \\ Naranjo Ugalde, ${ }^{2}$ Lais Angélica Ceruto \\ Ortiz, ${ }^{3}$ Yudith Escobar Bermúdez, ${ }^{4}$ Pedro \\ Rolando López Rodríguez ${ }^{5}$ \\ 'IGrade Specialist in Pediatric Intensive and Emergency \\ Medicine,William Soler Pediatric Cardiocenter, Havana, Cuba \\ 2II Degree Specialist in Cardiovascular Surgery, Associate \\ Professor, William Soler Pediatric Cardiocenter, Havana, Cuba \\ ${ }^{3} 4$ th year resident in Cardiovascular Surgery, Instructor teacher, \\ William Soler Pediatric Cardiocenter, Havana, Cuba \\ ${ }^{4}$ First Degree Specialist in Neonatology, Assistant teacher, \\ William Soler Pediatric Cardiocenter, Havana, Cuba \\ ${ }^{5}$ Specialist in I Degree and II Degree in General Surgery, \\ Assistant Professor, Consulting Professor and Assistant \\ Researcher, Enrique Cabrera Cosío General Teaching Hospital, \\ Havana, Cuba
}

Correspondence: Pedro Rolando López Rodríguez, Nationa Hospital, Calle Continental No. 152 between Calle D'Strampes and Calle Goicuría, Sevillano, October 10, Havana, Cuba,

Tel+53764l3062,Email lopezp@infomed.sld.cu

Received: December 14, 2021 | Published: January 06, 2022

\section{Introduction}

Since March 2019 and given the few studies published in this regard, it was believed that the coronavirus caused purely respiratory symptoms; However, as the number of patients with Covid-19 increased, it was observed that cardiovascular disease contributed to the worsening of the disease and darkened the prognosis of the infection. Patients with a history of cardiovascular disease make up the group with the highest risk of morbidity and mortality. ${ }^{1,2}$ The data available to date indicate that COVID-19 can cause new cardiovascular complications or exacerbation of pre-existing cardiovascular diseases. It is estimated that myocardial injury can be found in between $7 \%$ and $17 \%$ of hospitalized patients, especially those admitted to the ICU. ${ }^{3}$ Patients with COVID-19 are atincreased risk of acute myocardial infarction, myocarditis, heart failure, shock, arrhythmias, and sudden death in the acute phase of the disease. ${ }^{4,5}$

In COVID-19, ground glass opacities can be seen on chest radiographs, radiographic features similar tocardiogenic pulmonary edema. $^{3,6}$

In Chinese series, between 0.8 and $2 \%$ morbidity is reported in pediatric patients. In one of the largest reports published in China, of 731 pediatric cases with COVID 19,90\% were classified as asymptomatic $(21 \%)$, mild $(58 \%)$ and moderate $(19 \%) .^{7}$ The clinical pictures are mild in most children, including infants, with short-term fever and catarrhal symptoms. However, even if they are mild cases, they can be an important source of transmissionof the virus. ${ }^{8}$ On July 5,2021 , in Cuba, children under 20 years old reached 630 and of them 562 in pediatric ages, accumulating a total of 29,583 to date. ${ }^{9}$
Transposition of the great vessels (TGA) is a congenital heart disease in which the aorta arises from the rightventricle (RV) and the pulmonary artery from the left ventricle (LV); which produces a pathological relationship of the cardiac structures. ${ }^{10}$

The prevalence of congenital cardiovascular malformations has not decreased; To this is added the serious epidemiological situation that not onlyour country is going through, but the world in general. ${ }^{11}$ Every year a limited group of patients with this heart disease is born, despite the vigilance and well-executed development of the Prenatal Diagnosis of Congenital Heart Disease program, together with this,family criteria to maintain the course of pregnancy and birth of the baby. ${ }^{12}$ The correction of this cardiovascular malformation has several solutions depending on the characteristics of the associated anatomy and ventricular functions. ${ }^{13}$ In this case, a physiological correction surgery was performed (Mustard Surgery), ${ }^{13}$ consisting of crossing theatrial circulation. In such a way that the desaturated blood from the vena cava goes to the left ventricle, the pulmonary artery and the lungs and the oxygenated blood from the pulmonary veins goes to the right ventricle, the aorta and the rest of the body ${ }^{13}$ In the literature consulted, no reports of extracorporeal circulation surgery for congenital heart disease were found in children who suffered from Covid 19 disease, which motivates this presentation.

\section{Presentation of the case}

Eleven-month-old male, white, with prenatal diagnosis by Transposition Echocardiography of the Great Arteries; in which anatomical correction surgery was contraindicated due to early detraining of the left ventricle, which was under outpatient follow- 
up to carry out the planned surgery (Surgery ofMustard), previous Rashkind and with previous medical treatment for his underlying heart disease with Furosemide (10mg), aldactone (12mg) and Digoxin (40Mcg); At seven months of age, she began with an acute respiratory picture of light polypnea, nasal discharge with obstruction, intercostal drawing, and $\mathrm{SO} 2$ of $73 \%$. Ag test and PCR were performed withpositive results and his hospital admission was decided with a positive Covid-19 diagnosis. He was admitted to a Pediatric Intensive Care Unit since a history of congenital heart disease is a risk factor associated with severe clinical forms and complications. ${ }^{14}$

The complementary examinations carried out reported:

Hemoglobin: 17g / dl Hematocrit: 0.54 Leukocytes: 15x109/ 1 Segmented: 14\% Lymphocytes: 84\% Platelet count: 302 x10 9/1 Creatinine: $67 \mathrm{mmol} / 1$ Glycemia: 7.3mmol / 1, D-dimer positive, with slight metabolic and lactic acidosis $5.1 \mathrm{mmol} / 1$. Chest radiograph with evidence of bilateral inflammatory-looking lesions (Figure 1).

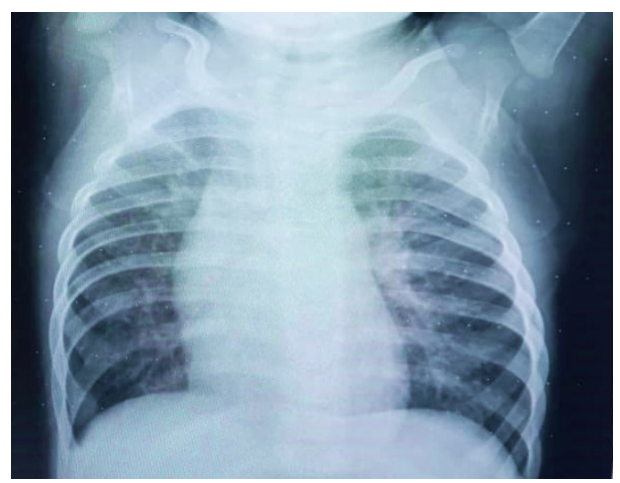

Figure I AP chest X-ray. Bilateral inflammatory lesions are seen.

\section{Positive covid}

During admission, invasive mechanical ventilation was not necessary, he underwent symptomatic treatment ${ }^{15}$ for fever with dipyrone, administration of fraxiheparin $(0.3 \mathrm{vial} / 12 \mathrm{~h})$ for 5 days and required antibiotic therapy with Ceftriazone for a period of 10 days at doses of $150 \mathrm{mg} / \mathrm{kg} /$ day, as well as dexamethazone.Under the criteria of clinical and radiological improvement, as well as the Covid-19 infection ruled out through a virological study, the patient was discharged after 20 days, with subsequent follow-up.He was evaluated during three months after discharge by Cardiology at the William Soler Cardiocenter, serial evaluation of EKG and chest X-ray.

The chest X-ray showed microatelectasis lesions and slight pulmonary edema.

Echocardiogram (Figure 2):

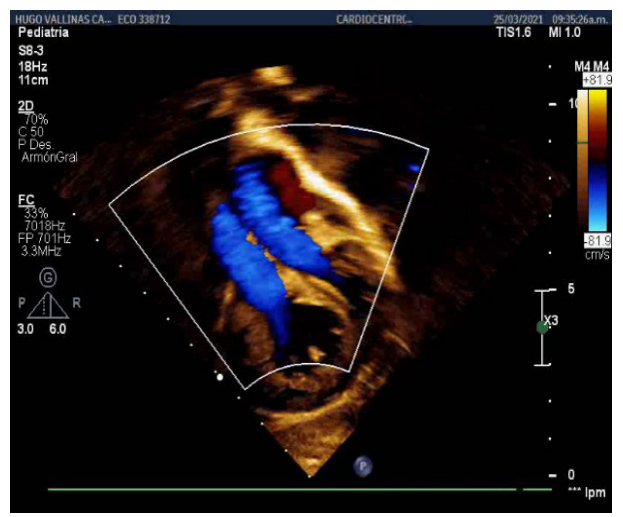

Figure 2 Echocardiogram. Double barrel image.
Transposition of the great vessels with closed ventricular septum, Boston type III, Aorta to the right and slightly anterior to the pulmonary. $15 \mathrm{~mm}$ balloon atrioseptostomy with left to right shunt. Moderate tricuspid regurgitation with TAPSE $=18 \mathrm{~mm}$.

After three months of convalescence and without evidence of sequelae from the viral infection, surgical intervention was decided. Mustard surgery was performed for definitive physiological correction, with extracorporeal circulation time of 113 minutes, aorticclamping time of 62 minutes at 23 degrees of temperature and modified hemofiltration once the extracorporeal circulation had concluded. Antimicrobial prophylaxis was used for 24 hours with Ceftriazone.

There were no complications during the surgical act and in the immediate postoperative period it evolved without major difficulties. Already in the PICU, he underwent treatment with captopril, aldactone and a diuretic pump. It was possible to separate from mechanical ventilation at 24 hours ofIt immediately evolved without major difficulties. Already in the PICU, he underwent treatment with captopril, aldactone and a diuretic pump. It was possible to separate from mechanical ventilation at 24 hours ofoperated with adequate tolerance and without risk of failure at weaning, with SO2> 97\%. On the third postoperative day, he presented a rhythm disorder (Figure 3) (bradycardia with complete atrioventricular block) that required placement of an external pacemaker, this complication is frequent in this type of surgery, secondary to atrial.

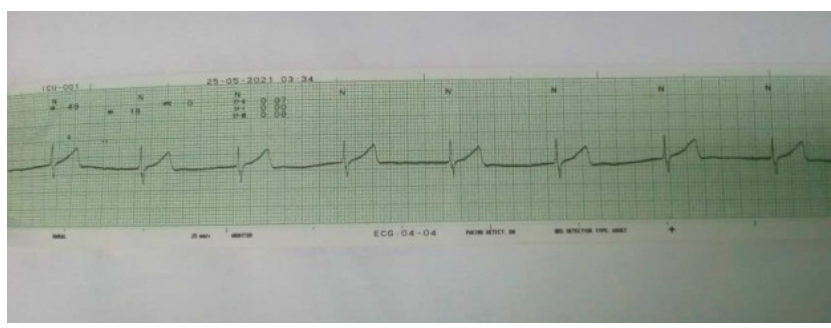

Figure 3 EKG. Complete A-V lock.

After an 8-day stay in the PICU, he was transferred to the open ward where he was admitted under treatment and monitoring for another 15 days.

Hospital discharge at 23 days with treatment and monitoring by Cardiology and Cardiovascular Surgery, without complications or immediate sequelae.

\section{Discussion}

The current pandemic produced by Covid-19 also affects the Cuban population, until June 2021 more than one hundred and ninety thousand people have been infected, with more than a thousand deaths. Despite the fact that children were less affected at the beginning, the new strains have ahigher incidence in children, with the development of severe forms that can trigger admissions to the PICU. Damage to the cardiovascular system is frequent, between. $8-20 \% .{ }^{16}$ The most reported cardiovascular manifestations are palpitations, orthostatic hypotension, hypertensive debut, myocarditis, pericarditis, rhythm disorders, and syncope. ${ }^{16}$

The case study is an infant who suffered from the disease in the period when physiological correction surgerywas planned for his underlying heart disease. Such surgeryit requires adequate pulmonary functional capacity and pulmonary pressures within adequate parameters for tolerance. ${ }^{17}$ The dysfunction can be asymptomatic, this justifies the need for close medical supervision.Stress tests in adults or adolescents may help prognosis, which is impossible in infants. 
When the dysfunction is advanced, the symptoms of heart failure appear, with respiratory distress, edema, fatigue, etc.n this phase the prognosis is at least reserved. It requires vigorous pharmacological treatment. This put the patient in a dangerous position and where studies and evaluation of respiratory function were required.

The patient in the current report was evaluated for three months after post-Covid discharge, with chest X-ray, EKG and echocardiogram awaiting possible sequelae reported in other patients. During this period, the patient remainedwith oxygen saturation according to the cyanosis caused by his heart disease, without worsening respiratory dynamics and stable hemodynamics. Once this time had elapsed, it was decided to carry out surgery. Physiological correction was carried out with satisfactory results. The patient did not develop sequelae that hindered the cardiovascular postoperative period or prolonged mechanical ventilation. It is likely that the preoperative strategy andthe use of modified hemofiltration that improves the conditions of the cardiopulmonary block in the immediate postoperative period have contributed to the absence of sequelae and the promptness shown in the need for mechanical ventilation.Despite the absence of complications in this case, related to Covid-19 infection, working with the patient was a challenge; A multidisciplinary care team was in charge of the specialized care of this patient, anticipating in advance possible complications due to the unusual and novel association of theconvalescent state of an infant due to Covid-19 and a complex cardiovascular surgery. No association studies have been published at the international level that favor a comparative point.Every day is a new challenge for health professionals and comprehensive medical care is sustained on the basis of experience. New research will open the horizons, making the treatments against this little-known disease more and more accurate. Strict compliance with prevention measures will help reduce the contagion of our pediatric patients and obtain a better evolution inthose undergoing surgical treatment. The watchword is resilience, a commitment that each doctor has to grow in the face of adversity and create effective individualized strategies.

\section{Conclusion}

A period of no less than three months with monitoring of respiratory and cardiovascular sequelae could offer safety for congenital heart disease surgery with the use of extracorporeal circulation in infants who have suffered from Covid 19.

\section{Conflicts of interest}

The autors declare that does not exist an interest conflict.

\section{Authors' contribution}

Ilen Corrales Arredondo: she formulated the general objective of the article, looked for information and updated scientific evidence. Drafting of the document and its supervision.

Alfredo Mario Naranjo Ugalde: Led the planning of the report, as well as its mentoring and validation. Final revision of the manuscript.

Lais Angélica Ceruto Ortiz: She searched for updated scientific information and evidence. She performed the English translation and final revision of the manuscript. She narrowed the bibliographic references according to Vancouver standards. Sheperformed the
English translation and final revision of the manuscript. She narrowed the bibliographic references according to Vancouver standards. She wrote the document.

Yudith Escobar Bermúdez: she managed information data for the discussion of the case. She searched for up-to-date scientific evidence and information.

Pedro Rolando López Rodríguez: He searched for updated scientific information and evidence. Final revision of the manuscript.

\section{References}

1. Xiong T, Redwood S, Chen M, et al. Coronavirus and the cardiovascular system: acute and long-ter implications. Eur Heart J. 2020;0:1-3.

2. Zheng YY, Ma YT, Zhang JY, et al. COVID-19 and the cardiovascular system. Nat Rev Cardiol. 2020.

3. Driggin E, Madhavan MV, Parikh SA. Irving Medical Center. Columbia University." Cardiovascular Considerations for Patients, Health Care Workers, and Health Systems during the COVID-19 Pandem". Journal of the American Collage of Cardiology 2020;75(18):2352-2371.

4. Figueroa Triana JF, Salas Márquez DA, Cabrera Silva JS, et al. COVID-19 y enfermedad cardiovascular. Sociedad Colombiana de Cardiología y Cirugía Cardiovascular. RevColombCardiol. 2020;27(3):166-174.

5. Kuba K, Imai $Y$, Rao $S$, et al. Lessons from SARS: Control of acute lung failure by the SARS receptor ACE2. J Mol Med. 2006;84(10):814-20.

6. Molina MM. Secuelas y consecuencias de la COVID-19.2020;13(2):71-77.

7. Márquez-Aguirre MP, Gutiérrez-Hernández A, Lizárraga-López SL, et al. Espectro clínico de COVID-19, enfermedad en el paciente pediátrico. Acta Pediatr Méx. 2020;41(Supl 1):S64-S71.

8. Calvo C, Tagarro A, Otheo E, et al. Actualización de la situación epidemiológica de la infección por SARS-CoV-2 en España: Comentarios a las recomendaciones de manejo de la infección en pediatría. Cartas cientificas. 2020;92(4):239-240.

9. Sitio Web Oficial. Ministerio de Salud Pública. 2021.

10. Cullum LM. The Natural History of Childrens with Transposition of the Great Vessels. MD Thesis. Cleveland, Ohio: Case Western Reserve University School of Medicine; 1967.

11. Chih Lin C, Hernández Del Rio, Jorge E. Hospital Civil Fray Antonio Alcalde. Cardiovascular and Metabolic Science. Cardiopatías congénitas. 2020;4(31)

12. Armas Padrino I. Cuba con alta detección prenatal de Cardiopatias Congénitas. 2019

13. Albert HM. Surgical correction of transposition of the great vessels. Surg Fórum. 1955;5:74-77.

14. Protocolo de Actuación Nacional para la covid-19. Cuba.

15. De Carvalho-Panzeri C AP, Brunow-de Carvalho W, Johnston C, et al. COVID-19 Diagnostic and Management Protocol for Pediatric Patients. Clinics. 2020;75:e1894.

16. Hu H, Ma F, Wei X, et al. Coronavirus fulminant miocarditis treated with glucocorticoid and human immunoglobulin. Eur Heart J. 2020;190.

17. Villagrá Albert Sandra. Transposición de grandes arterias operada con técnica de Mustard o Senning. Evolución a largo plazo. Unidad de Cardiopatias Congénitas (UCC). 